\title{
The promoting effect of chelating ligands in the oxidative carbonylation of phenol to diphenyl carbonate catalyzed by $\mathrm{Pd}-\mathrm{Co}$-benzoquinone system
}

\author{
Andrea Vavasori, Luigi Toniolo * \\ Department of Chemistry, University of Venice, Dorsoduro 2137, 30123 Venice, Italy
}

Received 3 February 1999; accepted 27 May 1999

\begin{abstract}
The system $\mathrm{Pd}(\mathrm{OAc})_{2} / \mathrm{BQ} / \mathrm{Co}(\mathrm{acac})_{3}(\mathrm{BQ}=$ benzoquinone), in combination with tetrabutylammonium bromide (TBAB) as a surfactant agent and a chelating ligand such as 2,9-dimethyl-1,10-phenanthroline (dmphen) or 2,9-dimethyl-4,7-diphenyl-1,10-phenanthroline (dmdpphen), is an efficient catalyst for the oxidative carbonylation of phenol to diphenyl carbonate (DPC). The best results have been obtained using the system $\mathrm{Pd}(\mathrm{OAc})_{2} / \mathrm{BQ} / \mathrm{Co}(\mathrm{acac})_{3} / \mathrm{dmphen}=1 / 30 / 8 / 5$ (molar ratio) in which $[\mathrm{Pd}]=10^{-3} \mathrm{~mol}^{-1}$ and $\mathrm{TBAB} / \mathrm{Pd}=60 / 1$. This system gives the maximum productivity of 700 $\mathrm{mol} \mathrm{DPC} / \mathrm{mol} \mathrm{Pd} \mathrm{h}$ at $135^{\circ} \mathrm{C}$ and under $P_{\text {tot }}=60 \mathrm{~atm}\left(\mathrm{CO} / \mathrm{O}_{2}=10 / 1\right.$ molar ratio). The role of each component of the catalytic system is discussed and a catalytic cycle is proposed. (c) 2000 Elsevier Science B.V. All rights reserved.
\end{abstract}

Keywords: Chelating ligands; Oxidative carbonylation; Pd-Co-benzoquinone system

\section{Introduction}

The industrial method commonly employed for the synthesis of diphenyl carbonate (DPC) is based on the reaction between phenol and phos-

Abbreviations: DPC, Diphenyl carbonate; TBAB, Tetrabutylammonium bromide; $\mathrm{BQ}$, p-benzoquinone; $\mathrm{H}_{2} \mathrm{BQ}$, Hydroquinone; AcO, Acetate; acac, Acetylacetonate; bipy, 2,2'-bipyridyl; phen, 1,10-phenanthroline; dmphen, 2,9-dimethyl-1,10phenanthroline; dpphen, 2,9-diphenyl-1,10-phenanthroline; dmdpphen, 2,9-dimethyl-4,7-diphenyl-1,10-phenanthroline

* Corresponding author. Tel.: +0039-41-2578553; fax: +0039-41-2578517; E-mail: toniolo@unive.it gene in the presence of bases [1]. Because the current trend in the chemical industry is to reduce the risks connected with the use of highly toxic substances such as phosgene [2], several alternative methods have been developed or proposed. Among them, the one-step oxidative carbonylation of phenol to DPC [1-4] is one of the most attractive methods.

Palladium (II) compounds are able to promote the non-catalytic carbonylation which occurs with concomitant reduction of $\mathrm{Pd}(\mathrm{II})$ to $\operatorname{Pd}(0)$ complexes or to Pd metal [5-9]. The catalytic oxidative carbonylation of phenol to DPC can be achieved in the presence of a 
cocatalyst able to reoxidize reduced $\mathrm{Pd}(0)$ to $\mathrm{Pd}(\mathrm{II})$ [10-17]. In this reaction, the key step is the reoxidation one. In order to obtain an efficient catalytic cycle, a multistep electron transfer system is used [10-17] in combination with a surfactant agent. Easier in situ regeneration of $\mathrm{Pd}(\mathrm{II})$ from $\mathrm{Pd}(0)$ is obtained by a synergetic effect of two oxidant cocatalysts such as Co$(\text { acac })_{3}\left(\right.$ or $\left.\mathrm{Cu}(\mathrm{acac})_{2}\right)$ and $(\mathrm{BQ})$ [10]. In these studies, simple transition metal salts were employed. The best results were obtained by using a $\mathrm{Pd}(\mathrm{OAc})_{2} / \mathrm{BQ} / \mathrm{Co}(\mathrm{acac})_{3}$ system in the ratio $1 / 30 / 3$, in the presence of tetrabutylammonium bromide (TBAB) as a surfactant agent
$(\mathrm{TBAB} / \mathrm{Pd}=60 / 1)$. At $140^{\circ} \mathrm{C}$, under a constant pressure of $50 \mathrm{~atm}\left(\mathrm{CO} / \mathrm{O}_{2}=10 / 1\right)$, the productivity was $400 \mathrm{~mol} \mathrm{DPC} / \mathrm{mol} \mathrm{Pd} \mathrm{h}$.

Since in general, ligand coordination plays a key role in the catalytic activity of the $\mathrm{Pd}(\mathrm{II})$ compounds, in principle, a further improvement of the $\mathrm{Pd} / \mathrm{Co} / \mathrm{BQ} / \mathrm{TBAB}$ catalytic system should be obtained by the addition of a dosed quantity of a proper ligand. We tested a series of different $\mathrm{O}-\mathrm{O}, \mathrm{O}-\mathrm{N}, \mathrm{S}-\mathrm{N}$ and $\mathrm{N}-\mathrm{N}$ chelating ligands that are known to coordinate $\mathrm{Pd}$ and that, at the same time, are stable in the presence of oxygen or other oxidizing agents. Thereafter, the results of this investigation are discussed.

Table 1

The effect of some chelating ligands on the productivity

$\mathrm{Pd}(\mathrm{OAc})_{2}=0.01 \mathrm{mmol}, \mathrm{Co}(\mathrm{acac})_{3}=0.02 \mathrm{mmol}, \mathrm{PhOH}=80 \mathrm{mmol} ; \mathrm{TBAB} / \mathrm{Pd}=60 / 1, \mathrm{BQ} / \mathrm{Pd}=30 / 1$, ligand $/ \mathrm{Pd}=1 / 1 \mathrm{molar} \mathrm{ratios} ;$ $T=100^{\circ} \mathrm{C}, P=60 \mathrm{~atm}\left(\mathrm{CO} / \mathrm{O}_{2}=10 / 1\right)$.

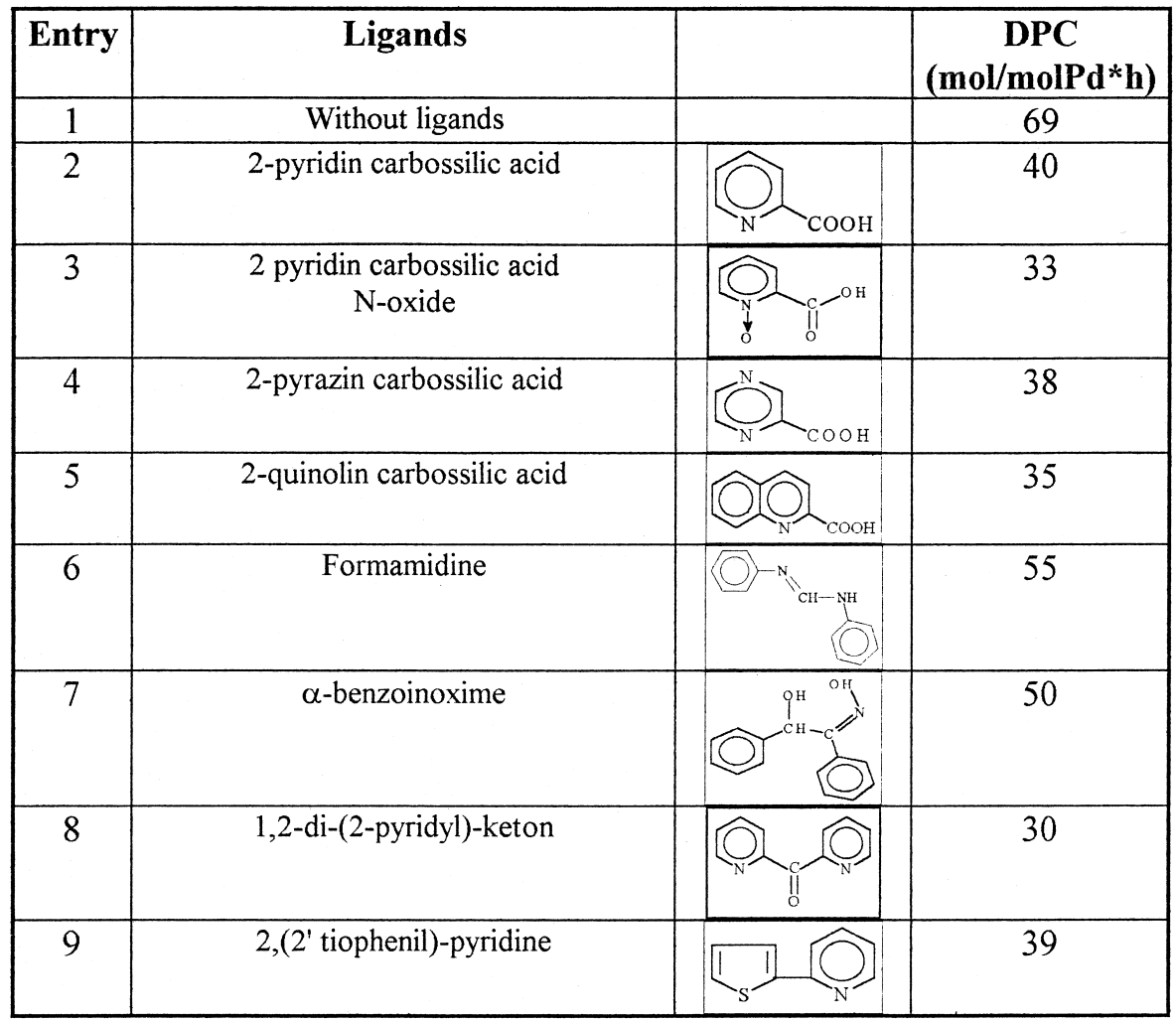




\section{Results and discussion}

\subsection{On the catalytic system}

The oxidative carbonylation of phenol to DPC occurs according to reaction (1):<smiles>O=C(Oc1ccc(OC(=O)[O+][C]2C=C[C+](O)C=C2)cc1)Oc1cccc(O)c1</smiles>

As already mentioned, the reaction is catalyzed by the system $\mathrm{Pd}(\mathrm{OAc})_{2} / \mathrm{BQ} / \mathrm{Co}(\mathrm{acac})_{3}$, in combination with a surfactant agent, such as TBAB. Typically, the components of the catalytic system were used in the ratio $\mathrm{Pd}$ $(\mathrm{OAc})_{2} / \mathrm{BQ} / \mathrm{Co}(\mathrm{acac})_{3} / \mathrm{TBAB}=1 / 30 / 3 / 60$, which are known to give satisfactory results [10]. This catalytic system can be improved in the presence of a bidentate $\mathrm{N}-\mathrm{N}$ substituted ligand such as 2,9-dimethyl-1,10-phenanthroline (dmphen) and 2,9-dimethyl-4,7-diphenyl-1,10phenanthroline (dmdpphen). For example using dmphen, under the conditions reported in Fig. 7 (see later), a productivity as high as $700 \mathrm{~mol}$ $\mathrm{DPC} / \mathrm{mol} \mathrm{Pd} \mathrm{h}$ can be achieved without formation of oxidative dimerization and trimerization by-products in a significant amount. However,

Table 2

The effect of $\mathrm{N}-\mathrm{N}$ chelating ligands on the productivity

$\mathrm{Pd}(\mathrm{OAc})_{2}=0.01 \mathrm{mmol}, \mathrm{Co}(\mathrm{acac})_{3}=0.02 \mathrm{mmol}, \mathrm{PhOH}=80 \mathrm{mmol} ; \mathrm{TBAB} / \mathrm{Pd}=60 / 1, \mathrm{BQ} / \mathrm{Pd}=30 / 1$, ligand $/ \mathrm{Pd}=1 / 1 \mathrm{molar} \mathrm{ratios} ;$ $\mathrm{T}=100^{\circ} \mathrm{C}, \mathrm{P}=60 \mathrm{~atm}\left(\mathrm{CO} / \mathrm{O}_{2}=10 / 1\right)$.

\begin{tabular}{|c|c|c|c|}
\hline Entry & Ligands & & $\begin{array}{c}\text { DFC } \\
\mathrm{mol} / \mathrm{molPd}^{*} \mathrm{~h}\end{array}$ \\
\hline 1 & Without ligands & & 69 \\
\hline 2 & 2,2'-bipyridyl & & $14^{*}$ \\
\hline 3 & $\begin{array}{l}\text { 1,10-phenantroline } \\
\text { (phen) }\end{array}$ & & $16^{*}$ \\
\hline 4 & terpyridine & & 18 \\
\hline 5 & $\begin{array}{l}\text { 2,9-methyl-1,10-phenantroline } \\
\text { (dmphen) }\end{array}$ & & 106 \\
\hline 6 & $\begin{array}{c}(2,9 \text { methyl })(4,7 \text { phenyl)-1,10-phenantroline } \\
\text { (dmdpphen) }\end{array}$ & $\mathrm{CH}_{3}^{\prime}$ & 110 \\
\hline 7 & $\begin{array}{l}2,9 \text { phenyl-1,10 phenantroline } \\
\text { (dpphen) }\end{array}$ & & 57 \\
\hline 8 & 4,7 phenyl-1,10 phenantroline & & 20 \\
\hline
\end{tabular}

\footnotetext{
* Using an excess of ligand $(\mathrm{N}-\mathrm{N} / \mathrm{Pd}=4 / 1)$, DPC was not detected.
} 
Table 3

The effect of preformed $\mathrm{Pd}(\mathrm{II})$ compounds on the productivity $\mathrm{Pd}(\mathrm{II})=0.01 \mathrm{mmol}, \mathrm{PhOH}=80 \mathrm{mmol} ; \mathrm{Co} / \mathrm{Pd}=2 / 1(\mathrm{~mol} / \mathrm{mol})$, $\mathrm{BQ} / \mathrm{Pd}=30 / 1, \quad \mathrm{TBAB} / \mathrm{Pd}=60 / 1 \quad(\mathrm{~mol} / \mathrm{mol}), \quad \mathrm{PhOH}=80$ $\mathrm{mmol} ; T=100^{\circ} \mathrm{C}, P=60$ atm $\left(\mathrm{CO} / \mathrm{O}_{2}=10 / 1\right)$; reaction time $=$ $5 \mathrm{~h}$.

\begin{tabular}{lll}
\hline Entry & Catalyst & $\begin{array}{l}\text { Productivity mol } \\
\mathrm{DPC} / \mathrm{mol} \mathrm{Pd} \mathrm{h}\end{array}$ \\
\hline 1 & $\mathrm{Pd}(\mathrm{OAc})_{2}$ & 69.2 \\
2 & $\mathrm{Pd}($ phen $)(\mathrm{OAc})_{2}$ & 10.5 \\
3 & $\mathrm{Pd}($ bipy $)(\mathrm{OAc})_{2}$ & 11.3 \\
4 & $\mathrm{Pd}($ dmphen $)(\mathrm{OAc})_{2}$ & 95.7 \\
5 & $\mathrm{Pd}(\mathrm{dmdpphen})(\mathrm{OAc})_{2}$ & 97.1 \\
\hline
\end{tabular}

carbon monoxide and oxygen are consumed also by a side reaction to carbon dioxide, which is also catalyzed by palladium compounds.

\subsection{Effect of chelating ligands on the productiv-} ity

In principle, in the case of palladium, of particular interest are chelating ligands that favour the square planar coordination, thus forcing the reagents (phenol and $\mathrm{CO}$ ) to interact in the catalytically more favoured cis position.

In Tables 1 and 2 are reported the chelating ligands tested together with the results obtained.

The catalytic system, without the addition of any ligand, gives a productivity of $69 \mathrm{~mol}$
$\mathrm{DPC} / \mathrm{mol} \mathrm{Pd} \mathrm{h}$ (Table 1 , entry 1 ). The productivity is depressed (40-30 mol DPC / mol Pd h) when the reaction is carried out in the presence of $\mathrm{O}-\mathrm{O}, \mathrm{N}-\mathrm{O}$ or $\mathrm{N}-\mathrm{S}$ chelating ligands (entry 2-9). Also, unsubstituted $\mathrm{N}-\mathrm{N}$ ligands do not improve the productivity (see Table 2 ).

For example, very low values (16-14 mol $\mathrm{DPC} / \mathrm{mol} \mathrm{Pd}$ h) are obtained when a stoichiometric amount of $\mathrm{N}-\mathrm{N}$ ligand, such as bipyridyl (entry 2) or 1,10-phenanthroline (entry 3), is added. A low productivity (10.5 and $11.3 \mathrm{~mol}$ $\mathrm{DPC} / \mathrm{mol} \mathrm{Pd} \mathrm{h}$ ) is obtained also when the preformed catalyst $\mathrm{Pd}($ phen $)(\mathrm{OAc})_{2}$ or $\mathrm{Pd}$ (bipy)(OAc) ${ }_{2}$ (Table 3, entries 2 and 3) is used in place of the system $\mathrm{Pd}(\mathrm{OAc})_{2}-\mathrm{N}-\mathrm{N}$ ligand. The catalytic activity is completely inhibited when a excess of these ligands are used $(\mathrm{N}-\mathrm{N} / \mathrm{Pd}=4 / 1$, see footnotes of Table 2 , entries 2 and 3), probably due to the formation of the bischelate stable $\left[\mathrm{Pd}(\text { chelating })_{2}\right]^{2+}$ complex [18], which does not possess easily available coordination sites capable of interacting with reacting molecules (see the proposed catalytic cycle depicted in Scheme 1). The productivity decreases to low values (14 mol DPC $/ \mathrm{mol} \mathrm{Pd}$ h) also when a tris-chelate ligand such as terpyridine (Table 2, entry 4) is used, probably because there is in situ formation of a stable

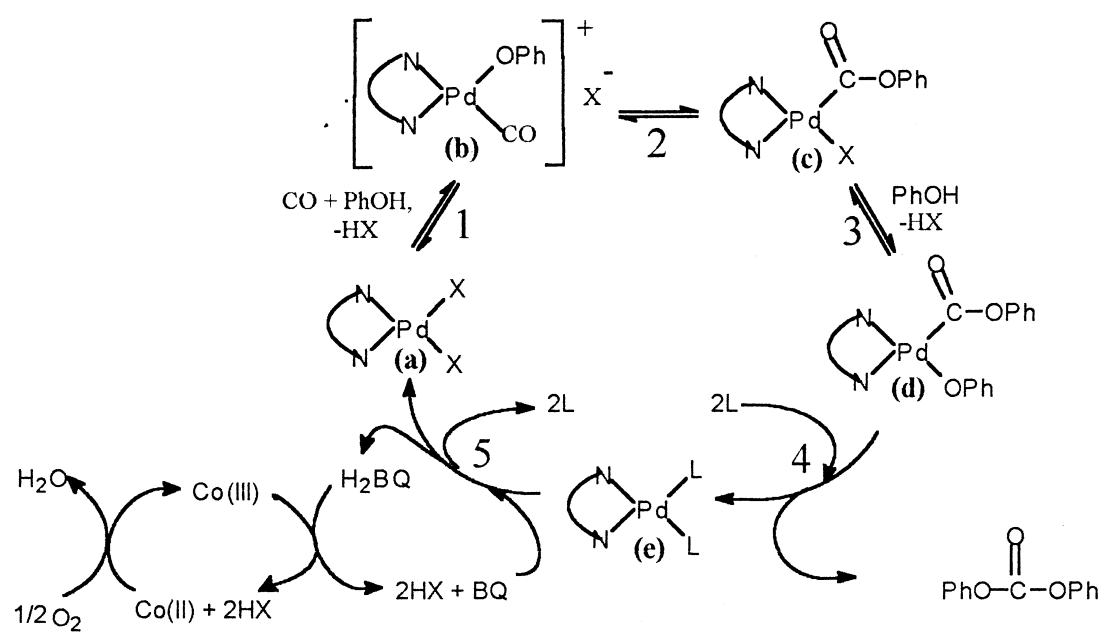

Scheme 1. 


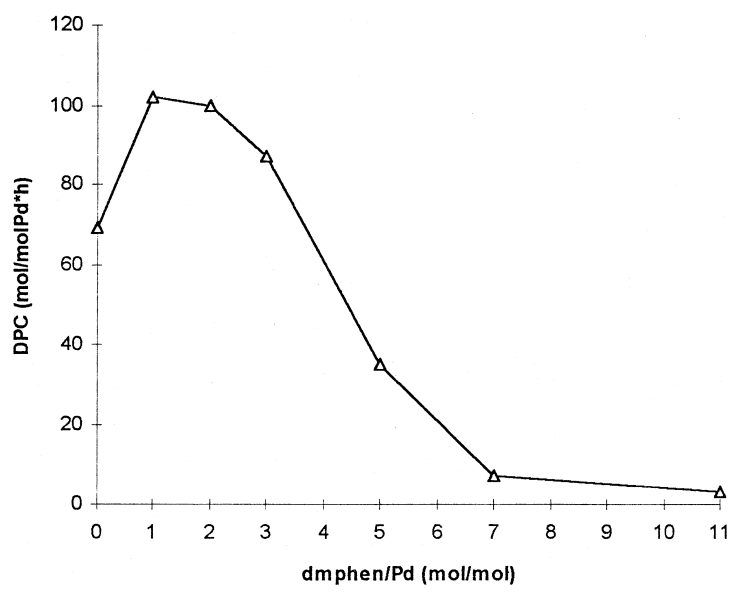

Fig. 1. Productivity as function of dmphen/Pd molar ratio. Run conditions: $\quad \mathrm{Pd}(\mathrm{OAc})_{2}=0.01 \mathrm{mmol}, \quad \mathrm{Co}(\mathrm{acac})_{3} / \mathrm{Pd}=2 / 1$ $(\mathrm{mol} / \mathrm{mol}), \mathrm{PhOH}=80 \mathrm{mmol} ; \mathrm{TBAB} / \mathrm{Pd}=60 / 1(\mathrm{~mol} / \mathrm{mol})$, $\mathrm{BQ} / \mathrm{Pd}=30 / 1(\mathrm{~mol} / \mathrm{mol}) ; \mathrm{P}=60 \mathrm{~atm}\left(\mathrm{CO} / \mathrm{O}_{2}=10 / 1 \mathrm{molar}\right.$ ratio), $\mathrm{T}=100^{\circ} \mathrm{C}$; reaction time $=4 \mathrm{~h}$.

tris-chelate complex such as $[\mathrm{Pd}(\mathrm{N}-\mathrm{N}-\mathrm{N}) \mathrm{X}]^{+}$, in which the coordination of two reagents, for example $\mathrm{PhO}^{-}$and $\mathrm{CO}$, is not favoured (see for example step 1 of the proposed catalytic cycle).

Quite interestingly, N-N ligands substituted with phenyl or methyl groups have a significant promoting effect. For example, using the dmphen ligand $(\mathrm{Pd} /$ ligand $=1 / 1)$, the productivity reaches $106 \mathrm{~mol} \mathrm{DPC} / \mathrm{mol} \mathrm{Pd}$ h (Table 2, entry 5). In Table 2, among the substituted phenanthrolines (entries 5-8), a sharp increase in productivity is observed going from phenanthroline (16 mol DPC/mol $\mathrm{Pd} \mathrm{h}$, entry 3) to 2,9-dimethylphenanthroline (106 mol DPC / mol $\mathrm{Pd}$ h, entry 5) and to 4,7-diphenyl-2,9-dimethylphenanthroline (110 mol DPC/mol Pd h, entry 6). This positive effect is probably due both to the increase of the ligand electron donor properties [19-21] as well as to the steric hindrance of the methyl groups.

The catalytic activity of the preformed precursor $\mathrm{Pd}(\mathrm{dmphen})(\mathrm{OAc})_{2}$ is close $(95 \mathrm{~mol}$ $\mathrm{DPC} / \mathrm{mol} \mathrm{Pd} \mathrm{h}$ ) to that obtained using the system $\operatorname{Pd}(\mathrm{OAc})_{2} / \mathrm{dmphen}=1 / 1 \quad(106 \mathrm{~mol}$ $\mathrm{DPC} / \mathrm{mol} \mathrm{Pd} \mathrm{h}$, see Table 3 ). This fact suggests that starting from this system, there is in situ formation of $\operatorname{Pd}(d m p h e n) X_{2}$.

\subsection{Optimization of the $\mathrm{Pd}(\mathrm{OAc})_{2} / \mathrm{BQ} /$ $\mathrm{Co}(\text { acac })_{3} / \mathrm{TBAB} /$ dmphen catalytic system}

Since the catalytic system $\mathrm{Pd}(\mathrm{OAc})_{2} / \mathrm{BQ} /$ $\mathrm{Co}(\mathrm{acac})_{3} / \mathrm{TBAB} / \mathrm{dmphen}$ is the most promising, we focused further investigations on the role of each component of this system.

\subsubsection{Effect of dmphen / Pd molar ratio on the productivity}

The productivity as a function of dmphen $/ \mathrm{Pd}$ molar ratio reaches a maximum at $\mathrm{dmphen} / \mathrm{Pd}$ $=1 / 1$ (Fig. 1). This fact suggests that the complex $\mathrm{Pd}(\mathrm{dmphen}) \mathrm{X}_{2}(\mathrm{X}=\mathrm{OAc}, \mathrm{Br})$, which may form in situ [18], plays an important role in the catalytic cycle.

At higher dmphen/Pd values, a significant decreasing in productivity is observed, which lowers to $7 \mathrm{~mol} \mathrm{DPC} / \mathrm{mol} \mathrm{Pd} \mathrm{h}$ when the dmphen/Pd molar ratio is $8 / 1$. This is probably due to the formation of the bischelate $\left[\operatorname{Pd}(\mathrm{dmphen})_{2}\right]^{2+}$ complex [18], which is inactive in this reaction.

\subsubsection{Role of the surfactant agent}

Fig. 2 shows that the presence of a surfactant agent $(\mathrm{TBAB})$ is essential in order to make the

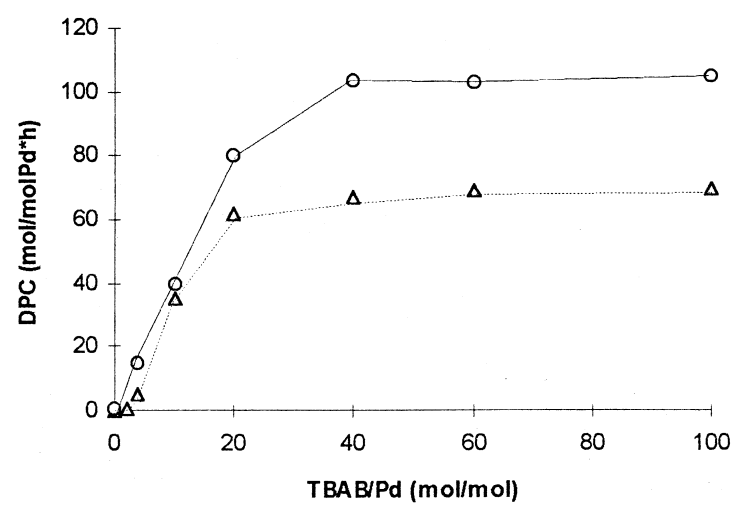

Fig. 2. Effect of the $\mathrm{TBAB} / \mathrm{Pd}$ molar ratio on the productivity. Run conditions: $\mathrm{Pd}(\mathrm{OAc})_{2}=0.01 \mathrm{mmol}, \mathrm{PhOH}=80 \mathrm{mmol}$, $\mathrm{BQ} / \mathrm{Pd}=30 / 1 ; \quad \mathrm{Co}(\mathrm{acac})_{3} / \mathrm{Pd}=3 / 1 \quad(\mathrm{~mol} / \mathrm{mol}) ; \quad \mathrm{O}$ : dmphen $/ \mathrm{Pd}=1 / 1(\mathrm{~mol} / \mathrm{mol}), \Delta:$ dmphen $/ \mathrm{Pd}=0 / 1 ; \mathrm{P}=60$ atm $\left(\mathrm{CO} / \mathrm{O}_{2}=10 / 1\right.$ molar ratio), $\mathrm{T}=100^{\circ} \mathrm{C}$, reaction time $4 \mathrm{~h}$. 


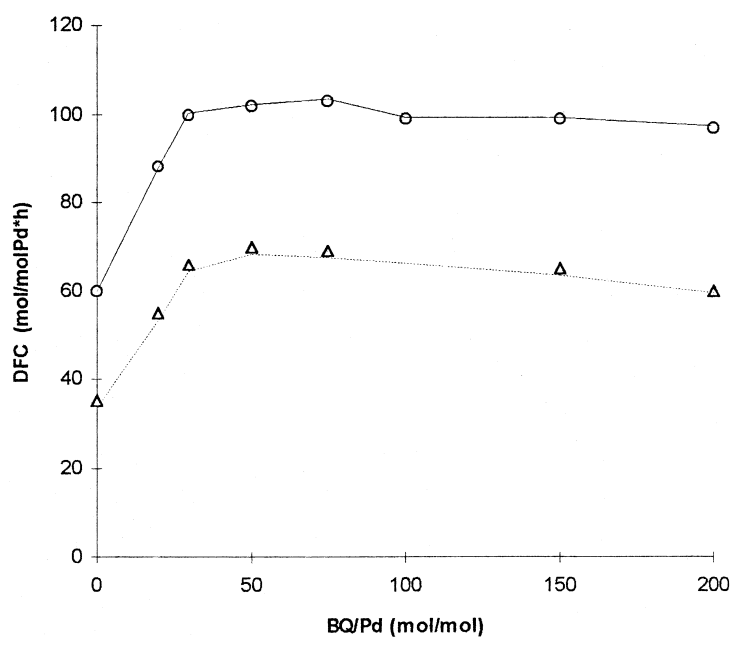

Fig. 3. Effect of the BQ/Pd molar ratio on the productivity. Run conditions: $\mathrm{Pd}(\mathrm{OAc})_{2}=0.01 \mathrm{mmol}, \quad \mathrm{Co}(\mathrm{acac})_{3} / \mathrm{Pd}=2 / 1$ (mol $/ \mathrm{mol}), \mathrm{PhOH}=80 \mathrm{mmol}$;BAB $/ \mathrm{Pd}=60 / 1(\mathrm{~mol} / \mathrm{mol}), \mathrm{O}$ : dmphen $/ \mathrm{Pd}=1 / 1(\mathrm{~mol} / \mathrm{mol}), \Delta: \mathrm{dmphen} / \mathrm{Pd}=0 ; \mathrm{P}=60$ atm $\left(\mathrm{CO} / \mathrm{O}_{2}=10 / 1\right.$ molar ratio), $\mathrm{T}=100^{\circ} \mathrm{C}$; reaction time $=4 \mathrm{~h}$.

catalytic cycle more efficient. The productivity reaches a plateau value of $105 \mathrm{~mol} \mathrm{DPC} / \mathrm{mol}$ $\mathrm{Pd} \mathrm{h}$ when the molar ratio $\mathrm{TBAB} / \mathrm{Pd}$ is larger than $40 / 1$. When the reaction is carried out without TBAB or in the presence of a small amount of it (TBAB $/ \mathrm{Pd} \ll 40 / 1)$, the productivity is low and Pd metal is found at the end of each reaction.

In addition, Fig. 2 shows that, in the absence of the dmphen ligand, the productivity reaches a plateau at c.a. $70 \mathrm{~mol} \mathrm{DPC} / \mathrm{mol} \mathrm{Pd} \mathrm{h}$ when $\mathrm{TBAB} / \mathrm{Pd}=40 / 1$. The comparison of the two curves suggests that the dmphen increases the productivity, but can not avoid the $\mathrm{Pd}$ metal formation and the catalyst deactivation at low $\mathrm{TBAB} / \mathrm{Pd}$ value.

Thus, it is reasonable to suppose that the surfactant properties of the TBAB cation plays an important role. As a matter of fact, it has been found that in the presence of such surfactant, there is formation of nanostructured $\mathrm{R}_{4} \mathrm{~N}^{+} \mathrm{X}^{-}$-stabilised metal clusters [22-25]. In these systems, each cluster is surrounded by a monomolecular layer of ammonium salt (micelle) which functions as a stabiliser and prevents agglomeration to larger naked metal particles [24]. In the present case, it is reasonable to suppose that the surfactant inhibits palladium metal agglomeration efficiently when the ratio $\mathrm{TBAB} / \mathrm{Pd}$ is $>40 / 1$, thus making easier its reoxidation to $\mathrm{Pd}(\mathrm{II})$.

\subsubsection{Effect on the productivity of p-benzo- quinone}

The BQ plays a fundamental role in the catalytic cycle (see Scheme 1) as it has been found when using a $\mathrm{Pd}-\mathrm{Co}$ catalytic system [10]. Fig. 3 shows that the productivity increases up to a plateau of $100 \mathrm{~mol} \mathrm{DPC} / \mathrm{mol} \mathrm{Pd} \mathrm{h}$ when the ratio $\mathrm{BQ} / \mathrm{Pd}$ is $>30 / 1$ and that the addition of dmphen has a positive effect on the catalytic system. In fact, both curves are similar, but the one related to the dmphen ligand is shifted to a higher productivity.

\subsubsection{Effect of Co/Pd molar ratio on the productivity}

Using a dmphen $/ \mathrm{Pd}=1 / 1$, the productivity increases in the presence of $\mathrm{Co}(\mathrm{III})$ and reaches a maximum of $106 \mathrm{~mol} \mathrm{DPC} / \mathrm{mol} \mathrm{Pd} \mathrm{h} \mathrm{when}$ $\mathrm{Co} / \mathrm{Pd}=3 / 1$ (Fig. 4). For high $\mathrm{Co} / \mathrm{Pd}$ values $(\mathrm{Co} / \mathrm{Pd}>4 / 1)$, a slight decrease in productivity is observed until a constant value of c.a. 65 $\mathrm{mol} \mathrm{DPC} / \mathrm{mol} \mathrm{Pd} \mathrm{h}$. This value is close to the

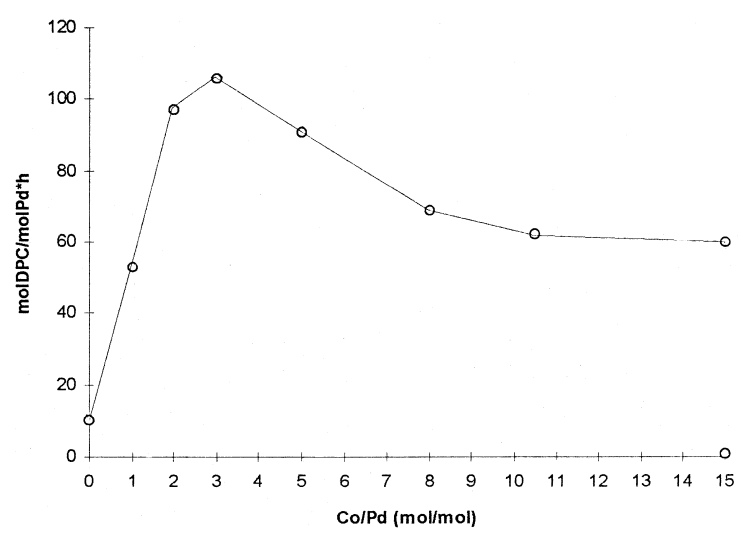

Fig. 4. Productivity as function of $\mathrm{Co} / \mathrm{Pd}$ molar ratio using dmphen $/ \mathrm{Pd}=1 / 1$. Run conditions: $\mathrm{Pd}(\mathrm{OAc})_{2}=0.01 \mathrm{mmol}$, $\mathrm{PhOH}=80 \mathrm{mmol}$; dmphen $/ \mathrm{Pd}=1 / 1(\mathrm{~mol} / \mathrm{mol}), \mathrm{TBAB} / \mathrm{Pd}=$ $60 / 1 \quad(\mathrm{~mol} / \mathrm{mol}), \quad \mathrm{BQ} / \mathrm{Pd}=30 / 1 \quad(\mathrm{~mol} / \mathrm{mol}) ; \quad \mathrm{P}=60 \quad \mathrm{~atm}$ $\left(\mathrm{CO} / \mathrm{O}_{2}=10 / 1\right.$ molar ratio $), \mathrm{T}=100^{\circ} \mathrm{C}$; reaction time $=4 \mathrm{~h}$. 


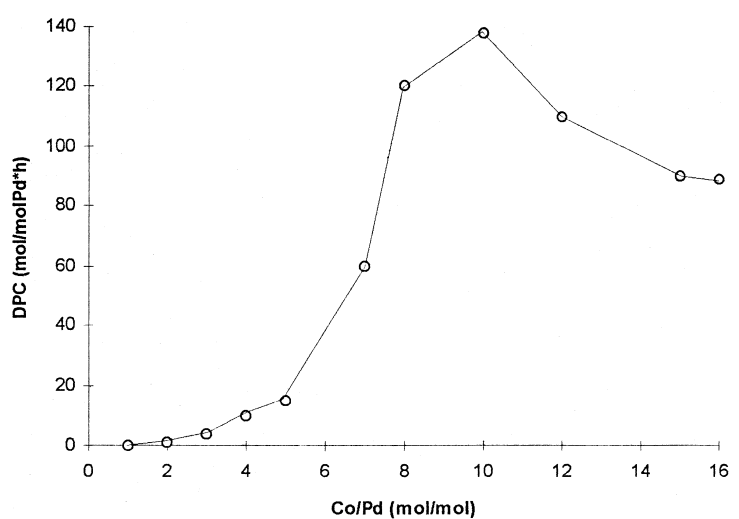

Fig. 5. Productivity as function of $\mathrm{Co} / \mathrm{Pd}$ molar ratio using dmphem $/ \mathrm{Pd}=8 / 1$. Run conditions: $\mathrm{Pd}(\mathrm{OAc})_{2}=0.01 \mathrm{mmol}$, $\mathrm{PhOH}=80 \mathrm{mmol} ; \mathrm{dmphen} / \mathrm{Pd}=8 / 1(\mathrm{~mol} / \mathrm{mol}), \mathrm{TBAB} / \mathrm{Pd}=$ $60 / 1 \quad(\mathrm{~mol} / \mathrm{mol}), \quad \mathrm{BQ} / \mathrm{Pd}=30 / 1 \quad(\mathrm{~mol} / \mathrm{mol}) ; \quad \mathrm{P}=60 \quad \mathrm{~atm}$ $\left(\mathrm{CO} / \mathrm{O}_{2}=10 / 1\right.$ molar ratio $), \mathrm{T}=100^{\circ} \mathrm{C}$; reaction time $=4 \mathrm{~h}$.

one obtained without addition of any ligands (Table 1, entry 1).

These results suggest that dmphen forms a complex also with $\mathrm{Co}$ (III) in competition with $\operatorname{Pd}(\mathrm{II})$, thus shifting equilibrium (2) to the right.

$\left[\mathrm{Pd}(\mathrm{dmphen}) \mathrm{X}_{2}\right] \rightleftharpoons \mathrm{PdX}_{2}+$ dmphen

A further support to this hypothesis has been found by studying the effect of $\mathrm{Co} / \mathrm{Pd}$ ratio on the productivity under the experimental conditions in which the productivity is very low (7 mol DPC $/$ mol Pd $\mathrm{h}$ using dmphen $/ \mathrm{Pd}=8 / 1$ and $\mathrm{Co} / \mathrm{Pd}=3 / 1)$. We have found that the productivity is again function of the $\mathrm{Co} / \mathrm{Pd}$ molar ratio and increases up to a maximum of $110 \mathrm{~mol} \mathrm{DPC} / \mathrm{mol} \mathrm{Pd} \mathrm{h,} \mathrm{when} \mathrm{the} \mathrm{molar} \mathrm{ratio}$ $\mathrm{Co} / \mathrm{Pd}$ increases to $12 / 1$ (see Fig. 5).

As already mentioned, at high concentration of ligand, the productivity is rather low, probably because there is formation of relatively large amounts of inactive $\left[\mathrm{Pd}(\mathrm{dmphen})_{2}\right]^{2+}$. The productivity can be improved by adding increasing amounts of $\mathrm{Co}(\mathrm{acac})_{3}$ (see Fig. 5). This fact can be explained also with the formation $\mathrm{Co}-$ dmphen complexes. Upon increasing the concentration of $\mathrm{Co}(\mathrm{acac})_{3}$, an increasing amount of ligand is subtracted to $\mathrm{Pd}(\mathrm{II})$ thus shifting equilibrium (3) to the more active $\mathrm{Pd}$ - (dmphen) $\mathrm{X}_{2}$. The slight decrease in productivity observed at a ratio $\mathrm{Co} / \mathrm{Pd}>4 / 1$ gives further support to the suggestion on the role played by equilibrium (2).

$$
\begin{aligned}
& {\left[\operatorname{Pd}(\text { dmphen })_{2}\right]^{2+}+2 \mathrm{X}^{-}} \\
& \quad \rightleftharpoons\left[\operatorname{Pd}(\text { dmphen }) \mathrm{X}_{2}\right]+2 \text { dmphen }
\end{aligned}
$$

Fig. 6 shows the effect on the productivity varying both the $\mathrm{Co}$ and ligand concentration. According to the previous results, each curve reaches a maximum at different $\mathrm{Pd} / \mathrm{Co} / \mathrm{dmphen}$ ratios. Thus, it is possible to optimize the $\mathrm{Co} / \mathrm{dmphen} / \mathrm{Pd}$ ratios in order to obtain the highest productivity. In fact, using $\mathrm{Co} /$ dmphen $/ \mathrm{Pd}=8 / 5 / 1$, at $100^{\circ} \mathrm{C}$ and $60 \mathrm{~atm}$ $\left(\mathrm{CO} / \mathrm{O}_{2}=10 / 1\right)$, a productivity as high as 170 mol DPC/mol Pd h can be obtained.

\subsubsection{Effect of the temperature on the produc-} tivity

The catalytic system, $\mathrm{Pd}(\mathrm{OAc})_{2} / \mathrm{BQ} /$ $\mathrm{Co}(\mathrm{acac})_{3} / \mathrm{dmphen}=1 / 30 / 8 / 5$, has been tested also at different temperatures. Fig. 7 shows that the productivity increases by increasing the temperature and reaches the maximum value of $700 \mathrm{~mol} \mathrm{DPC} / \mathrm{mol} \mathrm{Pd} \mathrm{h}$ at $135^{\circ} \mathrm{C}$.

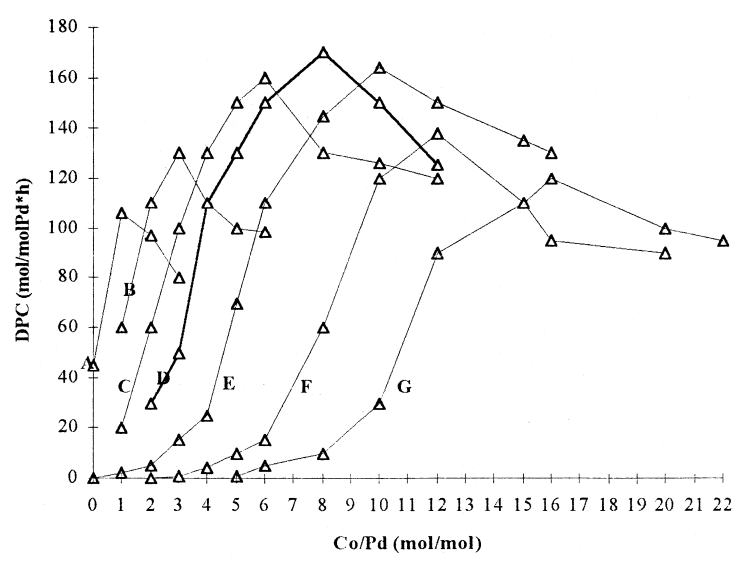

Fig. 6. Productivity as function of $\mathrm{Co} / \mathrm{Pd}$ and dmphen/Pd molar ratios. Run conditions: $\mathrm{Pd}(\mathrm{OAc})_{2}=0.01 \mathrm{mmol}, \mathrm{PhOH}=80 \mathrm{mmol}$; $\mathrm{TBAB} / \mathrm{Pd}=60 / 1(\mathrm{~mol} / \mathrm{mol}), \mathrm{BQ} / \mathrm{Pd}=30 / 1(\mathrm{~mol} / \mathrm{mol}) ; \mathrm{P}=$ $60 \mathrm{~atm}\left(\mathrm{CO} / \mathrm{O}_{2}=10 / 1\right.$ molar ratio $), \mathrm{T}=100^{\circ} \mathrm{C}$; reaction time $=$ $4 \mathrm{~h}$. Each curve have a different dmphen/Pd value: A) $1 / 1$, B) $3 / 1$, C) $4 / 1$, D) $5 / 1$, E) $6 / 1$, F) $8 / 1$, G) $12 / 1(\mathrm{~mol} / \mathrm{mol})$. 


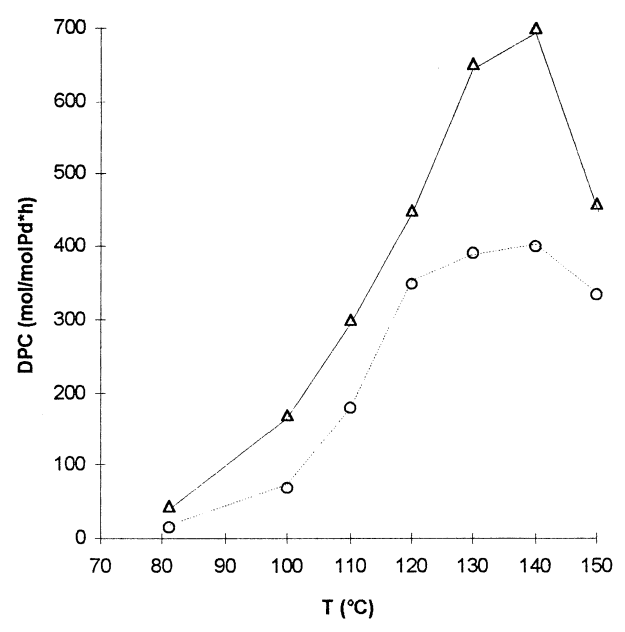

Fig. 7. Effect of the temperature on the productivity. Run conditions: $\mathrm{Pd}(\mathrm{OAc})_{2}=0.01 \mathrm{mmol}, \mathrm{PhOH}=80 \mathrm{mmol}$; $\mathrm{TBAB} / \mathrm{Pd}=$ 60/1 $(\mathrm{mol} / \mathrm{mol}), \quad \mathrm{BQ} / \mathrm{Pd}=30 / 1 \quad(\mathrm{~mol} / \mathrm{mol}) ; \quad \mathrm{O}$ : dmphen $/ \mathrm{Co} / \mathrm{Pd}=0 / 3 / 1, \triangle:$ dmphen $/ \mathrm{Co} / \mathrm{Pd}=1 / 8 / 5 ; \mathrm{P}=60$ $\operatorname{atm}\left(\mathrm{CO} / \mathrm{O}_{2}=10 / 1\right.$ molar ratio $)$, reaction time $=4 \mathrm{~h}$.

The lowering in the productivity, observed upon increasing the temperature above $140^{\circ} \mathrm{C}$, is probably due to side reactions of $\mathrm{BQ}$ with phenol which yields mixtures containing dimeric, trimeric compounds and polymers [26]. As a matter of fact, a large amount of a brown polymer, together with $\mathrm{Pd}$ metal, is found at the end of each reaction carried out above $140^{\circ} \mathrm{C}$.

\subsection{On the catalytic cycle}

In the proposed catalytic cycle (Scheme 1), the $\mathrm{Pd}-$ chelating ligand complex (a) $(\mathrm{X}=\mathrm{OAc}$ or $\mathrm{Br}$ ) is the catalyst precursor that interacts with the phenol and $\mathrm{CO}$ to give complex (b) and HX. These ligands are forced in a cis mutual coordination, thus making easier the insertion of $\mathrm{CO}$ into the $\mathrm{Pd}-\mathrm{OPh}$ bond to form intermediate (c). Complex (c) coordinates a second phenate species with formation of $\mathrm{HX}$ and $\mathrm{PdL}(\mathrm{COOPh})(\mathrm{OPh})(\mathbf{d})$. The reductive elimination from (d) gives rise to $\mathrm{DPC}$ and a $\operatorname{Pd}(0)$ complex (e). The reaction becomes catalytic: (i) when an efficient reoxidation system for $\operatorname{Pd}(0)$ to $\mathrm{Pd}(\mathrm{II})$ is used and, (ii) when a surfactant agent is added in order to avoid the catalyst deactivation due to the aggregation and precipitation of inactive $\mathrm{Pd}$ metal particles [10].
The reoxidation system proposed [10], is a multistep electron transfer system (see Scheme 1) composed of $p$-benzoquinone, which is reduced to hydroquinone in the presence of acid $\mathrm{HX}$, reoxidizes $\mathrm{Pd}(0)$ to $\mathrm{Pd}(\mathrm{II})$, and of a metal cocatalyst which is reduced by hydroquinone, reoxidized to $p$-benzoquinone. Oxygen and protons, arising from the last reaction, close the cycle with reoxidation of the reduced cocatalyst and formation of water.

\section{Experimental section}

\subsection{Materials}

Carbon monoxide and oxygen (purity higher then $99 \%$ ) were supplied by SIAD Spa (Italy). Phenol 99\%, biochemical grade, TBAB 99\% and 1,4-benzoquinone (BQ) 99\% were purchased from Acros Chemicals. Pd(OAc) $298 \%$, $\mathrm{Co}(\mathrm{acac})_{3}$ 98\%, 2,2'-bipyridyl-1,10-phenanthroline, 2,9-dimethyl-1,10-phenanthroline, 2,9-diphenyl-1,10-phenanthroline, 2,9-dimethyl-4,7diphenyl-1,10-phenanthroline, 2-pyridinecarboxylic acid, 2-pyridinecarboxylic acid $N$ oxide, 2-quinolinecarboxylic acid, $\alpha$-benzoinoxime, 1,2-di(2-pyridyl)ketone and terpyridine were purchased from Aldrich Chemicals. The $\mathrm{Pd}($ phen $)(\mathrm{OAc})_{2}, \quad \mathrm{Pd}(\mathrm{dmphen})(\mathrm{OAc})_{2}, \quad \mathrm{Pd}-$ (dmdpphen)(OAc) $)_{2}, \mathrm{Pd}($ bipy $)(\mathrm{OAc})_{2}$ palladium complexes were prepared according to methods reported in the literature [18].

\subsection{Experimental setup}

All the experiments were carried out in a stainless steel autoclave of c.a. $100 \mathrm{~cm}^{3}$ of capacity, provided with a magnetic stirrer. In order to avoid corrosion, the reagents were added to a glass beaker placed inside the autoclave.

Carbon monoxide and oxygen were supplied from a gas reservoir connected to the autoclave through a constant pressure regulator. The autoclave was provided with a temperature control $\left( \pm 0.5^{\circ} \mathrm{C}\right)$ and sampling of gas phase. 


\subsection{Experimental procedure}

Typical reaction conditions were: $T=100^{\circ} \mathrm{C}$, $P=60$ atm $\left(\mathrm{CO} / \mathrm{O}_{2}=10 / 1^{1}\right.$ molar ratio $)$, phenol $=80 \mathrm{mmol}$ (reagent and solvent in these reactions), $\mathrm{Pd} /$ cocatalyst $/ p$-benzoquinone $=$ $1 / 2 / 30$ and ligand $/ \mathrm{Pd}=1 / 1$ molar ratios, with $\mathrm{Pd}(\mathrm{OAc})_{2}=0.01 \mathrm{mmol}$, reaction time $4 \mathrm{~h}$. Tetrabutylammonium bromide, $\mathrm{Pd} / \mathrm{TBAB}=$ $1 / 60$ molar ratio, was also added to the reaction mixture.

In a typical experiment, known quantities of the catalyst, cocatalyst, $\mathrm{BQ}, \mathrm{TBAB}$ and ligand along with the solvent (phenol) where charged into the glass bottle placed in the autoclave. Then, the autoclave was pressurized at room temperature with the mixture of carbon monoxide and oxygen. The autoclave was then heated to the working temperature while stirring. At this temperature, the pressure in the autoclave was adjusted to $60 \mathrm{~atm}$ and maintained constant using the pressure regulator connected to the gas reservoir. The gas consumption was measured by monitoring the pressure drop of the reservoir. After $4 \mathrm{~h}$, the autoclave was cooled to room temperature and vented.

Products were characterized by gas chromatography analysis (GC) on a HP 5890 series II apparatus equipped with a $30 \mathrm{~m} \times 0.53 \mathrm{~mm}$ $\times 0.1 \mu \mathrm{m}$ FFAP column. The gas phase products $\left(\mathrm{CO} / \mathrm{CO}_{2}\right.$ molar ratio) were analyzed by $\mathrm{GC}$ using an $18 \mathrm{ft} \times 1 / 8 \mathrm{SS}$ Silica Gel, $60 / 80$ packed column.

\section{Acknowledgements}

This work was carried out with the financial support of the Ministero della Ricerca Scien-

\footnotetext{
${ }^{1}$ In all experiments the two gases were employed in this ratio to make sure to operate with a safe non explosive oxygen containing gas mixture.
}

tifica e Tecnologica, Programma Nazionale di Ricerca per la Qualita' della Vita. We thank Dr. P. Cesti and Dr. M. Ricci for the helpful comments.

\section{References}

[1] A.G. Shaikh, S. Sivaram, Chem. Rev. 96 (1996) 951.

[2] Y. Ono, Pure Appl. Chem. 68 (1996) 367.

[3] A.G. Shaikh, S. Sivaram, Ind. Eng. Chem. Res. 31 (1992) 1167.

[4] M. Takagi, H. Miyagi, T. Yoneyama, Y. Ohgomori, J. Mol. Catal. A: Chem. 129 (1998) L1.

[5] R.A. Lucky, G.E. Morris, The British Petroleum, EP 220863 A1, 1987.

[6] J.E. Hallgren, R.O. Matthews, J. Organomet. Chem. 175 (1979) 135

[7] J.E. Hallgren, G.M. Lucas, R.O. Matthews, J. Organomet. Chem. 204 (1981) 135.

[8] I.I. Moiseev, M.N. Vargaftik, T.V. Chernysheva, T.A. Stromnova, A.E. Gekhman, G.A. Tsirkov, A.M. Makhlina, J. Mol. Catal. 108 (1996) 77.

[9] I.I. Moiseev, T.A. Stromnova, M.N. Vargaftik, J. Mol. Catal. 86 (1994) 71.

[10] A. Vavasori, L. Toniolo, J. Mol. Catal. (1998) in press.

[11] Chang, T. Chin-Teh, General Electric, EP 0350697 A2, 1990.

[12] M. Mizukami, K. Hayashi, Mitsubishi Gas Chemical, EP 0572980 A2, 1993.

[13] H. Kezuka, F. Okuda, Idemitsu Kosan, EP 0503581 A2, 1992.

[14] Chang, T. Chin-Ten, General Electric, EP350700 A2, 1990.

[15] J.A. King, T.E. Krafft, G.R. Faler, General Electric, US5142086, 1991

[16] J.A. King, General Electric, EP 450442 A1, 1991.

[17] A. Heumann, K.J. Jens, M. Reglier, Palladium complex catalyzed oxidation reactions, Progress in Inorganic Chemistry 42 (1994) 542-556.

[18] B. Milani, E. Alessio, G. Mestroni, A. Sommazzi, F. Garbassi, E. Zangrado, N. Bresciani-Pahor, L. Randaccio, J. Chem. Soc. Dalton Trans. (1994) 1903.

[19] A.A. Schild, G.F. Smith, J. Phys. Chem. 60 (1956) 1546.

[20] M. Charton, J. Org. Chem. 31 (1966) 3739.

[21] A.A. Schilt, W.E. Dunbar, Tetrahedron 30 (1974) 401.

[22] H. Bonnemann, W. Brijoux, R. Brinkmann, E. Dinjus, T. Joussen, B. Korall, Angew. Chem., Int. Ed. Engl. 30 (1991) 1312.

[23] M.T. Reetz, W. Helbig, S.A. Quaiser, U. Stimming, N. Breuer, R. Vogel, Science 267 (1995) 367.

[24] N. Toshima, T. Takahashi, Bull. Chem. Soc. Jpn. 65 (1992) 400.

[25] J. Kiwi, M. Gratzel, J. Am. Chem. Soc. 101 (1979) 7214.

[26] H. Musso, Angew. Chem., Int. Ed. 2 (1963) 723. 